\title{
A study of maternal and fetal outcomes in critically ill obstetric patients
}

\author{
Fasiha Tasneem*, Vinutha M. Sharma
}

\begin{abstract}
Department of Obstetrics and Gynecology, Dr. Shankarrao Chavan Government Medical College, Nanded,
\end{abstract} Maharashtra, India

Received: 22 January 2020

Accepted: 28 February 2020

\author{
*Correspondence: \\ Dr. Fasiha Tasneem, \\ E-mail: fasiha.aziz@yahoo.com
}

Copyright: (C) the author(s), publisher and licensee Medip Academy. This is an open-access article distributed under the terms of the Creative Commons Attribution Non-Commercial License, which permits unrestricted non-commercial use, distribution, and reproduction in any medium, provided the original work is properly cited.

\begin{abstract}
Background: Pregnancy related morbidity is becoming a nightmare in Indian women. Some of these women end up in mortality and a few of them narrowly escape death. Critical care should be and is an authenticated part of obstetric practice. This study is an effort initiated to understand the risk of maternal morbidity, to investigate the contributing factors, foetal outcome, to study the adverse event, cause of maternal death and remedial measures.

Methods: All the obstetric cases admitted in Intensive care unit in a government institute in Maharashtra during January 2018 to June 2019 were analyzed prospectively. The indications for transfer into intensive care, risk factors, co morbidities if any were studied. Maternal and fetal morbidity and mortality were included in the study.

Results: During the study period, there were 10, 208 deliveries. There were 12 maternal deaths and 98 critically ill patients became morbid. Anemia is found to be a major pre-existing contributing factor (25.5\%) and an important risk factor making pregnancy become critical. DIC is found to be a major reason for ICU admission $(39.1 \%), 72.7 \%$ needed mechanical ventilator and $60.1 \%$ needed ionotropic support.

Conclusions: Anemia is a major problem still existing in our country. Gestational hypertension is another leading cause of critical illness in pregnancy. Identification of patients who are going downhill, timely referral to higher centers and appropriate management can improve both the maternal and the fetal outcomes.
\end{abstract}

Keywords: Critically ill, Ionotropic support, Intensive care unit, Mechanical ventilator, Near miss

\section{INTRODUCTION}

"God's interest in human race is nowhere better evidenced than in obstetrics, hence pregnancy is unique and special, let's make it safe" is a famous quote emphasizing the need of safe pregnancy and its outcome.

Maternal death was the mainstay to evaluate the health care services. But in recent times maternal morbidity has overshadowed maternal mortality. The transition of studying maternal mortality to morbidity is done as the number of maternal deaths have decreased and thus provide less information nowadays. Every minute every day, a woman dies as a result of pregnancy and childbirth somewhere in the world. ${ }^{1}$ It has been estimated that one woman per minute and 1600 women per day die due to pregnancy complications in the world. ${ }^{2}$ Every maternal death would be preceded by numerous morbidities. The World Health Organization (WHO) in the year 2004 estimated that 20 million women suffered from acute complications in pregnancy. ${ }^{3}$ These data are clearly indicating that pregnancy related morbidity is becoming a nightmare in Indian women. Some of these women end up in mortality and a few of them narrowly escape death with certain life-threatening condition called as near miss events. ${ }^{4}$

Because the pregnant woman is usually young and in good health her prognosis will hopefully be better if she receives timely intensive care than most of the other 
patients admitted in critical care unit. ${ }^{5}$ Hence, critical care should be and is an authenticated part of obstetric practice. Critically ill obstetric patient is defined as the one who because of normal or abnormal pregnancy, delivery and puerperium or because of the effects of systemic disease, develops complications threatening her life or for which she needs intensive monitoring, therapy or life support system. ${ }^{5}$

Hence, this study is an effort initiated to understand the risk of maternal morbidity, fetal outcome, to study the adverse event, to investigate the contributing factors and remedial measures and cause of maternal death. The study of this kind can guide future effective quality efforts and prevent the same in the future.

\section{METHODS}

The study is a prospective cross-sectional descriptive study of antepartum and postpartum women admitted in intensive care unit (ICU) from January 2018 to June 2019. This study conducted at a tertiary care centre in a district of Maharashtra with many primary health centers (RH and sub district hospitals) attached, with a few referrals being received from private hospitals too. The patients admitted in a well-equipped ICU are managed in collaboration with a team of anesthetist, physician, surgeon, obstetrician and pediatrician, respective residents and nursing staff.

\section{Inclusion criteria}

- All obstetric cases (pregnant and postpartum female up to 42 days) requiring intensive care

- Maternal deaths occurring in this institute during pregnancy and within 42 days of delivery

- Ectopic pregnancies

- Abortions

- Patients giving consent to be a part of the study.

\section{Exclusion criteria}

- All cases admitted beyond 42 days of postpartum with any medical or surgical complications

- All the cases admitted in general ward i.e. with no mortality or morbidity

- Maternal deaths occurring after 42 days of termination of pregnancy

- Patients who are not giving consent to be a part of the study.

\section{Statistical analysis}

Statistical analysis was done using MS excel.

\section{RESULTS}

During the study period, 10,208 deliveries took place in the institute, 110 patients were found to be critically ill who were admitted in medical-surgical ICU. This represents a prevalence of $1.07 \%$. Of these 110 patients, 98 patients had almost reached death but narrowly escaped it. The average intensive care unit (ICU) stay is found to be 11 days with a median being 9-15 days. The mean age of the patients was 23.99 with a range being $18-35$ years. Majority of the patients $(44.5 \%)$ in the age group of 20-23 years were found to be vulnerable to morbidity and mortality.

Table 1: Gestational age in critically ill patients.

\begin{tabular}{|ll|l|}
\hline Gestational age & No. of cases & Percentage \\
\hline Term & 54 & $49.1 \%$ \\
\hline Preterm & 34 & $30.9 \%$ \\
\hline Others & 22 & $20 \%$ \\
\hline Total & 110 & $100 \%$ \\
\hline
\end{tabular}

Table 2: Pre-existing contributing factors.

\begin{tabular}{|l|l|l|}
\hline Medical condition & No. of cases & Percentage \\
\hline Hypertension & 7 & $6.4 \%$ \\
\hline Heart disease & 4 & $3.6 \%$ \\
\hline Anaemia & 28 & $25.5 \%$ \\
\hline Epilepsy & 1 & $0.9 \%$ \\
\hline Tuberculosis & 2 & $1.8 \%$ \\
\hline Asthma & 2 & $1.8 \%$ \\
\hline Thyroid dysfunction & 2 & $1.8 \%$ \\
\hline
\end{tabular}

Of the 110 patients, $42(38.2 \%)$ were antenatal, 17 $(15.5 \%)$ were postnatal i.e. delivered in other hospitals and referred to the study hospital in postpartum period and 51 patients were intranatal, either in latent or in active phase of labor during admission. Unregistered antenatal cases $(82.7 \%)$ had significantly high mortality and morbidity when compared to registered cases. With increase in the number of pregnancies, the women become a high-risk case. This study shows $60 \%$ of the critically ill patients were multiparous. $3.7 \%$ of patients were grand multiparous. $60.9 \%$ underwent vaginal delivery of which $32.8 \%$ had spontaneous vaginal delivery and the rest had induced labor.

Table 3: Reason for ICU admission in critically ill patients.

\begin{tabular}{|l|l|l|}
\hline Reason & No. of cases & Percentage \\
\hline DIC & 43 & $39.1 \%$ \\
\hline HELLP & 15 & $13.6 \%$ \\
\hline Sepsis & 4 & $3.2 \%$ \\
\hline ARF & 12 & $10.1 \%$ \\
\hline ARDS & 4 & $3.6 \%$ \\
\hline Eclampsia & 25 & $22.7 \%$ \\
\hline PPH & 24 & $21.8 \%$ \\
\hline
\end{tabular}

A total $49.1 \%$ had term gestational age stating that the third trimester is another risk factor towards critical illness (Table 1). The others in Table 1 includes 3.6\% 
cases of abortion and $0.9 \%$ cases of ruptured ectopic pregnancy.

A total $25.5 \%$ of the cases had anemia as an important co morbidity, followed by chronic hypertension (6.4\%) and heart disease (3.6\%) (Table 2). DIC is the leading cause of ICU admission in this study (39.1\%) followed by eclampsia $(22.7 \%)$ and postpartum hemorrhage $(21.8 \%)$ (Table 3). DIC is largely due to gestational hypertension followed by hemorrhage. Patients got admitted into ICU due to more than one reason stated in the table too. A total $25.4 \%$ patients had neurological morbidity taken home whereas in patients who succumbed $33.3 \%$ had cardiac dysfunction. $10.1 \%$ patients had renal dysfunction necessitating the need for dialysis (Table 4). Among the broad interventions taken, $60.1 \%$ of the patients needed ionotropic support for their circulatory balance, $10.1 \%$ needed dialysis as they had renal failure. $72.7 \%$ needed ventilator support, $1.8 \%$ were aided with CPAP for their respiratory support (Table 5). $37.2 \%$ had to undergo certain surgical intervention of which a maximum $(9.1 \%)$ had stepwise devascularization. $62.7 \%$ patients were in need of frozen plasma and 55.5\% were in need of packed cell volume. Immediate and ample availability of blood and blood products have reduced maternal morbidity and mortality. $36.5 \%$ fetus were born healthy and $34.5 \%$ of fetus had intrauterine death. $6.3 \%$ of fetus had perinatal mortality (Table 6).

Table 4: Organ dysfunction in critically ill patients.

\begin{tabular}{|c|c|c|c|c|}
\hline \multirow[b]{2}{*}{ Conditions } & \multicolumn{2}{|l|}{ Morbidity } & \multicolumn{2}{|l|}{ Mortality } \\
\hline & $\begin{array}{l}\text { No. of critically } \\
\text { ill patients }\end{array}$ & Percentage & $\begin{array}{l}\text { No. of patients } \\
\text { who died }\end{array}$ & Percentage \\
\hline Hepatic dysfunction & 23 & $20.1 \%$ & 3 & $25 \%$ \\
\hline Renal dysfunction & 12 & $10.1 \%$ & 0 & $0 \%$ \\
\hline Respiratory dysfunction & 22 & $20 \%$ & 1 & $8.3 \%$ \\
\hline Cardiac dysfunction & 7 & $6.4 \%$ & 4 & $33.3 \%$ \\
\hline Cerebral dysfunction & 28 & $25.4 \%$ & 2 & $16.6 \%$ \\
\hline Coma & 4 & $3.6 \%$ & 3 & $25 \%$ \\
\hline Immunological dysfunction (sepsis) & 4 & $3.2 \%$ & 0 & $0 \%$ \\
\hline
\end{tabular}

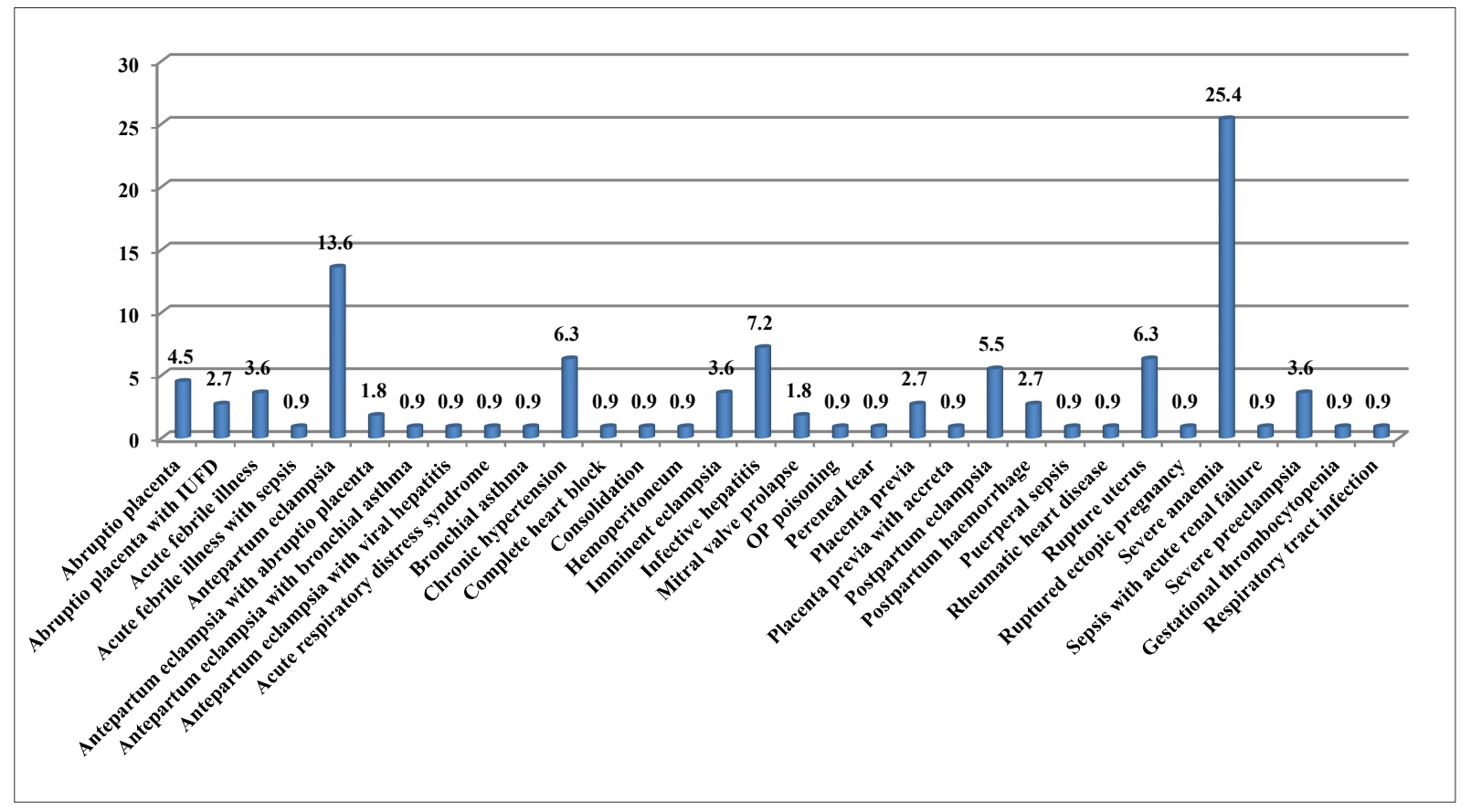

Figure 1: Risk factors in critically ill patients.

Severe anemia is found to be a major risk factor contributing around $25.4 \%$ of cases followed by antepartum eclampsia (13.6\%). Hypertensive disorder in pregnancy is found to be the most common direct cause of mortality in this study (Figure 1). Hypotensive shock is the most common complication met during the ICU stay 
(20.9\%) followed by infective hepatitis (10.9\%) (Figure 2 ). Since last few years, with clean delivery care and genuine use of antibiotics the rate of sepsis has come down. Even then a few cases of sepsis (4 cases, 3.6\%) were found in the study institute. As all of these 4 deliveries were conducted in primary and secondary health centers, appropriate knowledge regarding asepsis and clean delivery methods would minimize these rates too.

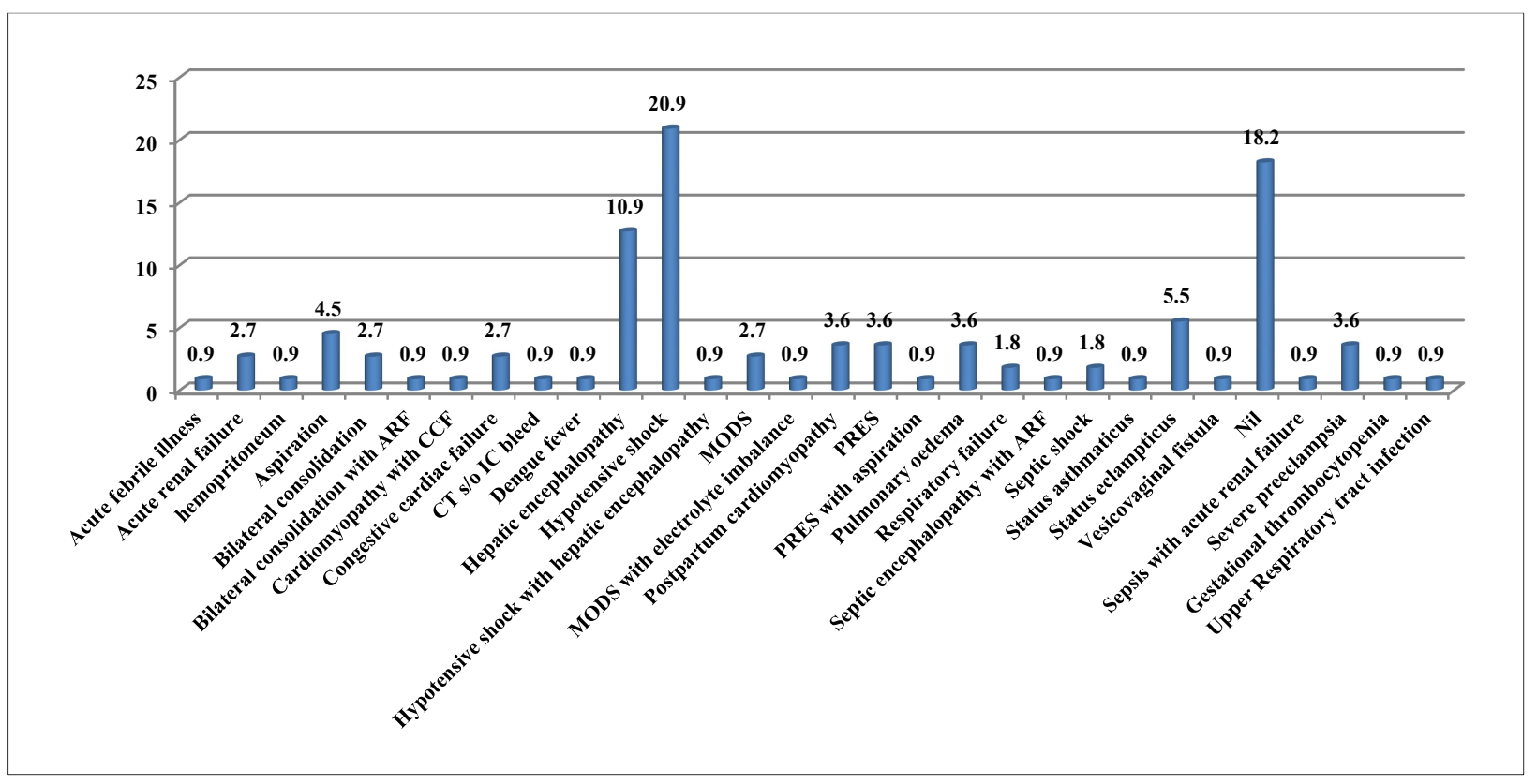

Figure 2: Course and complications during ICU stay.

Table 5: Broad interventions taken in critically ill patients.

\begin{tabular}{|lll|}
\hline Intervention & No. of cases & Percentage \\
\hline Ionotropic support & 67 & $60.1 \%$ \\
\hline Dialysis & 12 & $10.9 \%$ \\
\hline Ventilator support & 80 & $72.7 \%$ \\
\hline Surgical intervention & 31 & $28.2 \%$ \\
\hline On CPAP & 2 & $1.8 \%$ \\
\hline
\end{tabular}

Table 6: Fetal outcome in critically ill patients.

\begin{tabular}{|lll|}
\hline Fetal outcome & No. of cases & Percentage \\
\hline Healthy & 40 & $36.5 \%$ \\
\hline NICU admission & 17 & $15.5 \%$ \\
\hline IUFD & 38 & $34.5 \%$ \\
\hline Perinatal death & 7 & $6.3 \%$ \\
\hline
\end{tabular}

A total 77 patients were successfully discharged from the study hospital, 11 patients were referred to higher centres as dialysis is not available in the study institute and 12 cases expired of which 3 expired undelivered. 10 patients went discharge against medical advises (Table 7).

If anemia is complicating 28 lives in this study, 5 of these had mortality in their early admission hours. Out of these
5 patients, 2 patients expired undelivered, 1 expired in her 4 th stage of labor, 2 in their postnatal day one.

Table 7: Maternal outcome in critically ill patients.

\begin{tabular}{|c|c|c|}
\hline Maternal outcome & No. of cases & Percentage \\
\hline Discharged & 77 & $70 \%$ \\
\hline Against medical advise & 10 & $9.1 \%$ \\
\hline Referred to higher centre & 11 & $10 \%$ \\
\hline total maternal death & 12 & $10.1 \%$ \\
\hline Expired undelivered & 03 & $2.7 \%$ \\
\hline
\end{tabular}

Table 8: Cause of death in critically ill patients.

\begin{tabular}{|lll|}
\hline Cause of death & $\begin{array}{l}\text { No. of } \\
\text { cases }\end{array}$ & Percentage \\
\hline Severe anaemia with & 3 & $25 \%$ \\
\hline Congestive cardiac failure & 3 & $16.6 \%$ \\
\hline Hypotensive shock & 2 & $16.7 \%$ \\
\hline Postpartum cardiomyopathy & 2 & $16.7 \%$ \\
\hline Hepatic encephalopathy & 2 & $16.7 \%$ \\
\hline $\begin{array}{l}\text { Status eclamptic us with } \\
\text { pulmonary oedema }\end{array}$ & 2 & $8.3 \%$ \\
\hline $\begin{array}{l}\text { Postpartum eclampsia with } \\
\text { pulmonary oedema }\end{array}$ & 1 & \\
\hline
\end{tabular}


This depicts that the society is undernourished for not only children but also for pregnant women. Anemia can become a nightmare to an obstetrician if not corrected in her antenatal period (Table 8).

The ratio of morbidity: mortality cases is calculated and found to be $8.2: 1$ in this study. This explains that for every 8.2 cases who narrowly escaped death there was one death in the study institute. The higher the ratio the better is the care provided.

\section{DISCUSSION}

This study is associated with high rates of preventability of death by understanding the cause of mortality. Without identification and treatment, these patients would have landed up in death. The purpose of identification and evaluation of these cases is to facilitate opportunities for improvement in health care and avoid mortality.

The NFHS-3 (National Family Health Survey of India, conducted in 2005-2006) reported the main reasons behind high maternal mortality in India being ${ }^{5}$

- Deliveries not conducted by trained personnel

- Women not seeking antenatal care

- Postnatal care is grossly deficient.

Hence, noting all these details, effective measures are taken to identify, shift the mother immediately to intensive care unit and start appropriate line of management.

The mean age and the age group were almost similar to the study by Sinha et al. ${ }^{6}$ Though teenage pregnancy has come down in number, pregnancy and its complications are yet more seen in early 20s. Hence education to women, motivation to avoid child marriage, providing knowledge to teenagers regarding contraception should be encouraged. A study by Mustafa R showed a hospital stay ranging between 3 to 28 days. ${ }^{7}$ This study shows that maximum of the patients who were critically ill belonged to term gestational age which is consistent with the results by Ranatunga. ${ }^{8}$ Hence a keen supervision and follow up is needed during the last trimester and labor.

A study by Srinivas $\mathrm{S}$ et al, showed 60 were antepartum and 15 were postpartum. ${ }^{9}$ This study too had reports showing almost similar results reflecting that postpartum care is not sufficient enough in the health care system. Health care workers and a pregnant-women should be educated regarding the postpartum period and the complications that may arise. The study by Yellikar et al shows majority of their study subjects were unbooked. ${ }^{10}$ Our society is still unaware of the complications of pregnancy as a major proportion of pregnant women are still unbooked. The study of Ranatunga shows that 35 primipara, 52 multipara and 3 grand multipara patients became critically ill. $^{8}$ An increase in the parity of the women tends to make her a high-risk patient. Grand multipara is merely due to lack of education, social taboos regarding male child and lack of knowledge regarding contraception which is a preventable risk in morbidity and mortality. The study by Rakesh HJ tells, only 3 patients underwent spontaneous vaginal delivery, 18 underwent caesarean section and 4 underwent laparotomy for rupture uterus. ${ }^{11}$ In this study, one patient who was induced with certain inducing agent landed up in rupture uterus who needed laparotomy and other surgical interventions to save her life. Hence, a judicious use and proper knowledge regarding oxytocics and inducing agents is needed. The fetal outcome of this study is comparable with the study of Yellikar et al, which shows $48.3 \%$ of newborns were healthy, $38.5 \%$ newborns were admitted in NICU and $13.7 \%$ had still births. ${ }^{10}$ The study by Roopa PS, showed $44.2 \%$ cases of hemorrhage, $23.6 \%$ had hypertension and $4.5 \%$ had cardiac disease. $^{12}$

The study by Mustafa R, found $21.2 \%$ had anemia as a major contributing factor. ${ }^{7}$ The study by Smitha Srinivas 9 shows postpartum hemorrhage $(29.3 \%)$ followed by DIC $(16 \%)$ as major reasons for ICU admissions. Eclampsia (6.6\%) and HELLP (4\%) were the next reasons in their study. The study by mantel showed $26 \%$ had hypertension as a main reason. ${ }^{13}$ The study by Padmavati $\mathrm{P}$ shows respiratory $(13.3 \%)$, hepatic $(5.3 \%)$, renal $(4 \%)$ causes of morbidity. ${ }^{14}$ The study by Mustafa R shows cardiac, renal and cerebral organ dysfunction in cases of morbidity in the order. ${ }^{7}$

A study by Sreenivas S et al, concluded that $78.6 \%$ of their patients were in need of blood and blood products. ${ }^{7}$ Padmavati's P et al, study showed 46 patients needed ventilator support, 29 cases needed hemodynamic support, 4 needed dialysis and 2 needed surgical intervention. ${ }^{14}$ Most of the critically ill patients used ventilator and ionotropic support for their survival. The next most used is blood and blood products as seen in many studies.

The first most important risk factor is anemia followed by the next important risk factor is viral hepatitis affecting around 8 patients on admission. Acute viral hepatitis $\mathrm{E}$ has a fulminant course in pregnancy can be prevented by drinking clean and boiled water. ${ }^{11}$ Rupture uterus is another risk factor affecting the life of mother. About 6 patients had rupture uterus in the institute of which 5 patients had rupture due to scarred uterus and one patient had unscarred uterus rupture. Out of the 5 scarred rupture uterus, one patient had incomplete rupture with a live baby found in the uterine cavity, later on shifted to NICU. The study by Patil V showed severe preeclampsia being risk factor in $54.4 \%$, eclampsia in $6 \%$, antepartum hemorrhage in $7.73 \%$ and postpartum hemorrhage in $7.56 \%$ of their cases, 3 cases had rupture uterus as risk factors. ${ }^{15}$ The study done by Appinabhavi A, showed that 8 patients had hepatic encephalopathy, 9 patients had acute lung injury, 22 patients had MODS as complications. ${ }^{16}$ 


\section{CONCLUSION}

A $100 \%$ of the maternal deaths could be avoided and the morbidities (both maternal and fetal) could be minimized if only the malfunctioning of the health care system is rectified by frequent training of the staff and creating awareness at the grass root levels is done. Medical conditions such as anemia and hypertension should be treated in the antenatal period by appropriate facilities. Identification of high-risk factors in antenatal clinics at periphery should be done and these patients should be labelled as "high risk pregnancy". These patients should be referred to higher centres for appropriate and timely management. Early recognition of a patient going downhill before one or more systems are involved, prompt diagnosis, timely referral and adequate management can improve both the maternal and fetal outcomes. It is recommended that aggressive initiative should be taken for frequent training of medical officers and paramedical staffs working at periphery and their upgradation regarding management guidelines should be done.

Hence, the most vital purpose of this study is to improve clinical practice and minimize maternal mortality and morbidity through evidence-based medicine.

\section{Funding: No funding sources} Conflict of interest: None declared

Ethical approval: The study was approved by the Institutional Ethics Committee

\section{REFERENCES}

1. Tasneem F, Shanbhag V. Study of cases of double mishap in a tertiary care teaching hospital. Int $\mathrm{J}$ Reprod Contracept Obstet Gynecol. 2019;8:1650-4.

2. Azima S, Ashrafizaveh A, Gholamzade S, Kaviani M, Mousavi S, Bakhshayesh HR. Causes of maternal and perinatal mortality: a retrospective study. Inter $\mathbf{J}$ Curr Microbiol Appl Sci. 2015;4(3):733-9.

3. AbouZahr C. Global burden of maternal death and disability. Br Med Bull. 2003;67:1-11.

4. Verma S, Rai L, Kumar P, Pai MV, Shetty J. Near miss, obstetrics event and maternal deaths in a tertiary care hospital: an audit. J Preg. 2013:2013.

5. Bhadade R. Rosemarie de' Souza, Anirudha More and Minal Harde, maternal outcomes in critically ill obstetrics patients: a unique challenge. Indian $\mathrm{J}$ Critical Care Med. 2012;16(1):8-16.

6. Sinha M, Goel JK, Sah S, Goel R, Chaurasia R. Severe acute maternal morbidity: study of epidemiology and risk factors. Int $\mathrm{J}$ Reprod Contracept Obstet Gynecol. 2016;5:2141-5.

7. Mustafa R, Hashima H. Near-miss obstetrical events and maternal deaths. J Coll Phys Surg Pak. 2009;19(12)781-5.

8. Ranatunga G, Akbar J, Samarathunga S, Perera Y, Kariyawasam L, Kumarasiri J. Severe acute maternal morbidity in a tertiary care institute, Sri Lanka. J Obstet Gynecol. 2012;34:135-43.

9. Sreenivas K, Beevi N, Devi U. Clinical characteristics and outcome of obstetric patients who required mechanical ventilation in a tertiary care hospital in North Kerala. Indian $J$ Clin Pract. 2014;25(6):552-6.

10. Yellikar KA, Deshpande SS, Deshpande SF. Severe acute maternal morbidity in a tertiary care center with basic intermediate respiratory care unit setup. Int J Sci Stud. 2015;3(5):36-40.

11. Rakesh HJ, Diana V. Study of prevalence and factors associated with maternal near miss (MNM) cases and maternal death at Rajiv Gandhi Government Women and Children Hospital, Pondicherry, India. Int J Reprod Contracept Obstet Gynecol. 2018;7:1048-53.

12. Roopa PS, Verma S, Rai L, Kumar P, Pai MV, Shetty J. Research article "near miss" obstetric events and maternal deaths in a tertiary care hospital: an audit, Hindawi Publishing Corporation J Preg. 2013:Article ID 393758.

13. Mantel GD, Buchmann E, Rees H, Pattinso RC. Severe acute maternal morbidity: a pilot study of a definition for a near-miss. $\mathrm{Br} \mathrm{J}$ Obstet Gynecol. 1998;105:985-90.

14. Padmavati P. Critical care in obstetrics: a one year prospective study in a tertiary care hospital. IOSR J Dental Med Sci. 2017:30-43.

15. Patil V, Kamath V, Desai RM. Obstetric near miss events and maternal deaths in a tertiary care hospital. Int J Reprod Contracept Obstet Gynaecol. 2018;7:519-23.

16. Appinabhavi A, Panicker S, Rajkumar N. Maternal and perinatal outcomes in critically ill obstetric patients. Int J Reprod Contracept Obstet Gynecol. 2014;3(1):189-94.

Cite this article as: Tasneem F, Sharma VM. A study of maternal and fetal outcomes in critically ill obstetric patients. Int J Reprod Contracept Obstet Gynecol 2020;9:1570-5. 